\title{
Enterococcus faecalis surface proteins determine its adhesion mechanism to bile drain materials
}

Department of Medical Microbiology ${ }^{1}$ and Department of Biomedical Engineering ${ }^{2}$, University of Groningen, Hanzeplein 1, 9713 GZ Groningen, The Netherlands

\author{
Karola Waar, ${ }^{1}$ Henny C. van der Mei, ${ }^{2}$ Hermie J. M. Harmsen, \\ John E. Degener ${ }^{1}$ and Henk J. Busscher ${ }^{2}$
}

Author for correspondence: Karola Waar. Tel: +3150 3633510. Fax: + 31503633528 . e-mail:k.waar@med.rug.nl

\begin{abstract}
An important step in infections associated with biliary drains is adhesion of micro-organisms to the surface. In this study the role of three surface proteins of Enterococcus faecalis (enterococcal surface protein, aggregation substances 1 and 373) in the adhesion to silicone rubber, fluoro-ethylene-propylene and polyethylene was examined. Four isogenic $E$. faecalis strains with and without aggregation substances and one strain expressing enterococcal surface protein were used. The kinetics of enterococcal adhesion to the materials was measured in situ in a parallel plate flow chamber. Initial deposition rates were similar for all strains, whereas the presence of surface proteins increased the total number of adhering bacteria. Nearest neighbour analysis demonstrated that enterococci expressing the whole sex-pheromone plasmid encoding aggregation substances 1 or 373 adhered in higher numbers through mechanisms of positive cooperativity, which means that adhesion of bacteria enhances the probability of adhesion of other bacteria near these bacteria. Enterococci with the enterococcal surface protein did not adhere through this mechanism. These findings indicate that the surface proteins of $E$. faecalis play a key role in the adhesion to bile drains and bile drain associated infections.
\end{abstract}

Keywords: bacterial adhesion, positive cooperativity, infection, biliary drains, biomaterials

\section{INTRODUCTION}

After an operation involving the common bile duct (CBD), for instance a liver transplantation, the bile is often diverted for prolonged times using a bile drain (T-tube). Infections are a frequent complication of T-tubing of the CBD (Yu et al., 1996a). Normally, the biliary tract is sterile, but bacterial colonization occurs in up to $75 \%$ of patients within several weeks after insertion of an in-dwelling foreign body ( $\mathrm{Yu}$ et al., 1996a). Especially in immune-compromised liver transplant patients the bile may be drained with a T-tube for up to 3 months and infections pose a major problem (Ben-Ari et al., 1998). In animal experiments, T-tubing of the CBD resulted invariably in contamination of bile

Abbreviations: Agg, aggregation substance; $C B D$, common bile duct Esp, enterococcal surface protein; FEP, fluoro-ethylene-propylene; $P E$, polyethylene; SR, silicone rubber. by intestinal bacteria within 6 weeks (Koivusalo et al., 1996).

After insertion of the bile drain in the CBD, bilecolonizing bacteria may form a biofilm that can be a source of persistent infection, because the biofilm mode of growth protects the adhering bacteria against host defences and the action of antimicrobial agents (Costerton et al., 1999). The initial step in the formation of a microbial biofilm is the transport and adhesion of micro-organisms to the surface of the in-dwelling foreign body. This adhesion is often determined by the presence of a host-derived coating of the foreign body and different bacterial cell surface structures, like fimbriae, fibrillae or specific surface proteins (An \& Friedman, 1998; Bos et al., 1999; Busscher et al., 2000). In a physico-chemical approach, these specific structural and chemical cell surface properties are included in overall cell surface properties, as hydrophobicity and zeta potential (An \& Friedman, 1998; Bos et al., 1999; Busscher et al., 2000). Insight into the involvement of 
these bacterial surface properties in adhesion to biomaterials, as an important initial step in biofilm formation, may lead to strategies to reduce or prevent biomaterial-centred infections.

Enterococcus faecalis is one of the Gram-positive microorganisms commonly found in infections associated with foreign bodies in the bile duct (Ben-Ari et al., 1998; Molinari et al., 1996; Yu et al., 1996b). Due to the emerging antibiotic resistance of this micro-organism, these infections are often difficult to prevent or treat (Murray, 1990). Some surface proteins of E. faecalis are found more frequently in enterococci causing infections and are therefore reported to be associated with enterococcal adhesion and infection (Berti et al., 1998; Coque et al., 1995; Jett et al., 1994; Shankar et al., 1999). One of these proteins, aggregation substance (Agg), is encoded by sex-pheromone-responsive plasmids. Agg is expressed in response to peptide pheromone induction as a sticky 'hair-like' structure on the cell wall (Galli et al., 1989), resulting in formation of aggregates of donor and recipient bacteria and transfer of plasmids (Clewell, 1993). All sex-pheromone plasmids, except pAM373, contain a homologous DNA region that encodes Agg (e.g. Asa1 encoded on pAD1). The Agg encoded on plasmid pAM373 (Asa373) does not fit the overall homology as no similarities could be detected by Southern or Western blots using Asa1-specific DNA probes or antibodies (Galli \& Wirth, 1991; MuschollSilberhorn, 1999). Finally, the DNA sequence of asa373 proved to be totally different from the DNA sequence of asa1 (De Boever et al., 2000). The deduced amino acid sequence of Agg contains two tripeptide arginineglycine-aspartic acid (RGD) sequences (Galli et al., 1990). Since RGD is the cell attachment site of a large number of adhesive extracellular matrix, blood and cell surface proteins (Ruoslahti, 1996), it has been suggested that Agg might play a role in the adherence to, and the colonization of, host tissues by E. faecalis. This has been confirmed by different groups, showing that Agg is correlated with the binding of E. faecalis to renal tubular cells and intestinal epithelial cells (Kreft et al., 1992; Olmsted et al., 1994; Sartingen et al., 2000).

The second surface protein, enterococcal surface protein (Esp), was discovered in an E. faecalis strain that caused multiple infections within a hospital ward (Shankar et al., 1999). Recently, it was shown that the presence of the esp gene was highly associated with the capacity of E. faecalis to form a biofilm on a polystyrene surface (Toledo-Arana et al., 2001). Also, the presence of Esp contributed to colonization and persistence of E. faecalis in the urinary tract in an animal model of urinary tract infection (Shankar et al., 2001). A variant esp gene was found in vancomycin-resistant Enterococcus faecium spreading in hospitals (Willems et al., 2001). The fact that surface proteins Agg and Esp are associated with E. faecalis causing infections or epidemics suggests that these proteins may be associated with the ability of this micro-organism to adhere to and subsequently infect host tissue, or to spread within the hospital.

The purpose of this study was to investigate whether surface proteins Agg (Asa1 and Asa373), encoded on sex-pheromone-responsive plasmids, and Esp of E. faecalis influence its adhesion to different bile drain materials. To this end, we compared the adhesion of five E. faecalis strains with different surface proteins to fluoro-ethylene-propylene (FEP), polyethylene (PE) and silicone rubber (SR) under flow conditions similar to those in a bile drain.

\section{METHODS}

Strains and growth conditions. Four isogenic E. faecalis strains were used in this study: the plasmid-free strain OG1X (Ike et al., 1983); OG1X containing the sex-pheromoneresponsive plasmid pAD1, encoding the Agg Asa1, with a positive regulator gene inserted that induces constitutive expression of this plasmid (denoted as OG1XE:pAD1; E indicates the positive regulator gene) (Franke \& Clewell, 1981; Muscholl et al., 1993); OG1X containing the plasmid $\mathrm{pW}$-e-Asa1, a derivative of the Escherichia coli-Enterococcus faecalis shuttle vector $\mathrm{pWM} 401$ which contains the asa1 gene and constitutively expresses Asa1 but no other proteins encoded on pAD1 nor any proteins that might be encoded on the vector (Albrecht B. Muscholl-Silberhorn, Thetis-IBN, Hamburg, Germany, personal communication) (denoted as OG1X:pWeAsa1) (Muscholl et al., 1993); and OG1X containing the plasmid pAM373 which expresses Asa373 after induction with pheromones (denoted as OG1X:pAM373) (Clewell et al., 1985). The four isogenic OG1X-derived strains did not contain the esp gene, as confirmed by PCR. Expression of Agg was checked by immunofluorescence with polyclonal antibodies against Asa1 or Asa373. A similar level of Agg expression in all three Agg-positive strains was detected (data not shown). A. B. Muscholl-Silberhorn kindly provided OG1X strains and antibodies. V. Shankar (University of Oklahoma Health Sciences Centre, Oklahoma City, USA) provided MMH594, the Esp-expressing strain (Shankar et al., 1999). MMH594 did not express Agg, as confirmed by immunofluorescence.

The strains were streaked and grown overnight at $37^{\circ} \mathrm{C}$ from a frozen stock on blood agar plates. The plate was then kept at $4{ }^{\circ} \mathrm{C}$, but never longer than 4 weeks. Several colonies were used to inoculate $3 \mathrm{ml}$ Todd-Hewitt broth (Oxoid) that was incubated at $37^{\circ} \mathrm{C}$ in ambient air for $24 \mathrm{~h}$. From this preculture, $2 \mathrm{ml}$ was used to inoculate a second culture of $200 \mathrm{ml}$ THB that was grown for $18 \mathrm{~h}$. E. faecalis OG1X:pWeAsa1 was grown in THB with $20 \mu$ g erythromycin $\mathrm{ml}^{-1}$ and $20 \mu \mathrm{g}$ chloramphenicol ml${ }^{-1}$, and MMH594 was grown in THB with $500 \mu \mathrm{g}$ gentamicin $\mathrm{ml}^{-1}$. Bacteria from the second culture were harvested by centrifugation at $10000 \mathrm{~g}$ for $5 \mathrm{~min}$ at $10^{\circ} \mathrm{C}$ and washed twice with demineralized water. Subsequently, bacteria were sonicated on ice for $2 \times 10 \mathrm{~s}$ to separate cell clusters and counted in a Bürker-Türk counting chamber. The cells were resuspended in PBS $(10 \mathrm{mM}$ potassium phosphate, $0 \cdot 15 \mathrm{M} \mathrm{NaCl}, \mathrm{pH}$ 7) at a concentration of $3 \times 10^{8}$ cells ml ${ }^{-1}$.

E. faecalis JH2-2 excretes all known sex-pheromones of $E$. faecalis into the growth medium and was used to collect pheromone (Jacob \& Hobbs, 1974). After 24 h growth at $37^{\circ} \mathrm{C}$ in $\mathrm{THB}$, the culture was centrifuged at $10000 \mathrm{~g}$ for $10 \mathrm{~min}$ at $10^{\circ} \mathrm{C}$ and the supernatant containing the pheromones was autoclaved. To induce expression of Agg in strain OG1X:pAM373, cells must be cultivated in the presence of pheromone, therefore the second culture of strain OG1X:pAM373 consisted of $100 \mathrm{ml}$ fresh THB and $100 \mathrm{ml}$ pheromone-containing THB supernatant. 
Biomaterials. Implant-grade SR was obtained from Medin. Poly(tetrafluoroethylene-co-hexafluoropropylene) (fluoroethylene-propylene, FEP) was supplied by Fluorplast and low density PE from Goodfellow. To ensure biomaterial surfaces were clean, they were sonicated for $3 \mathrm{~min}$ in a surfactant solution (2\% RBS 35 in water; Omniclean), rinsed thoroughly with water and then washed with methanol and demineralized water before use.

Parallel plate flow chamber, image analysis and adhesion. The flow chamber (internal dimensions: $l \times w \times h, 76 \times 38 \times$ $0.6 \mathrm{~mm})$ and image analysis system have been described in detail previously (Busscher \& Van der Mei, 1995). Images were taken from the bottom plate $(58 \times 38 \mathrm{~mm})$ of the parallel plate flow chamber. The Perspex bottom plate was completely covered with the material under study for FEP and PE. For SR a thin square $(15 \times 15 \mathrm{~mm})$ of the material was affixed centrally into the groove $(15 \times 15 \mathrm{~mm})$ of a thicker $(2 \cdot 0 \mathrm{~mm})$ Perspex plate. The depth of the groove was adapted to the thickness of the biomaterial in such a way that the SR surface was at the same height as the surface of the Perspex plate. The top plate of the chamber was always made of glass. The flow chamber was cleaned with Extran (Merck) and thoroughly rinsed with water and demineralized water. Prior to each experiment, all tubes and the flow chamber were filled with PBS, taking care to remove all air bubbles from the system. Once the system was filled, a bacterial suspension of $3 \times 10^{8}$ cells $\mathrm{ml}^{-1}$ in PBS was allowed to flow through the system at a flow rate of $1.44 \mathrm{ml} \mathrm{min}^{-1}$, corresponding with a shear rate of $10 \cdot 6 \mathrm{~s}^{-1}$. This shear rate is similar to the shear rate in a bile drain of $2 \mathrm{~mm}$ diameter at a bile production of $30 \mathrm{ml} \mathrm{h}^{-1}$. Deposition was observed with a CCD-MXRi camera (High Technology) mounted on a phase-contrast microscope (Olympus $\mathrm{BH}-2$ ) equipped with a $40 \times$ ultra-long-working distance lens (Olympus ULWD-CD Plan 40 PL). The camera was coupled to an image analyser (TEA; Difa). The bacterial suspension was perfused through the system for $4 \mathrm{~h}$ with re-circulation at room temperature, and images were taken at different time intervals and analysed. All adhesion experiments were performed in triplicate with separately cultured bacteria. To exclude the influence of growth in the presence of the antibiotics erythromycin and chloramphenicol on the adhesion of strain OG1X:pWeAsa1, we tested the adhesion of this strain after growth in medium without antibiotics and the results fell within the range found for adhesion after growth in the presence of antibiotics (data not shown). However, as the vector used is very unstable if the bacteria are grown without antibiotics, strain OG1X:pWeAsa1 was grown in the presence of antibiotics for better reproducibility.

Statistical analysis. Data were analysed with one-way analysis of variance followed by the Bonferonni $t$-test for pairwise multiple comparisons. The Kruskal-Wallis test followed by the Mann-Whitney test were used for non-parametric data. Significance was defined as $P \leqslant 0 \cdot 05$.

\section{RESULTS}

To measure the adhesion of E. faecalis strains to different bile drain materials, a bacterial suspension was perfused through a flow chamber system for $4 \mathrm{~h}$ during which images were taken from the material with adhering bacteria. The number of adhering bacteria in the images were transformed to number of bacteria per unit area and least-square-fitted to an exponential curve. The number of bacteria adhering at the stationary end point, $n$ at $t_{\infty}$, could be estimated from this exponential curve (SigmaPlot for Windows, version 5.00; SPSS), as well as a characteristic time constant, $\tau$, describing the approach of the adhesion process to a stationary state (Dabros \& Van de Ven, 1982). The initial increase in the number of adhering bacteria over time was expressed as the socalled initial deposition rate, $j_{0}$, the increase in the number of adhering bacteria per unit area and time.

\section{Initial deposition rates}

In Table 1 the results of the flow chamber adhesion experiments are shown, including initial deposition rates $\left(j_{0}\right)$, characteristic adhesion times $(\tau)$ and number of bacteria at the stationary end point $\left(n\right.$ at $\left.t_{\infty}\right)$. The initial deposition rates $\left(j_{0}\right)$ did not differ for the E. faecalis strains with or without surface proteins on FEP and PE. On SR, however, the initial deposition rate of strain MMH594 was significantly higher than that of strain OG1X, while in addition the mean initial deposition rates, averaged for all strains, were significantly higher on FEP than on SR $(P \leqslant 0 \cdot 05)$. The experimentally observed initial deposition rates are all in excess of the theoretical initial deposition rate $\left(j_{0}^{*}\right)$ for deposition in the parallel plate flow chamber under the current experimental conditions according to Von Smoluchowski-Levich, i.e. $692 \mathrm{~cm}^{-2} \mathrm{~s}^{-1}$ (Bowen et al., 1976). Consequently, the mean deposition efficiency $\left(j_{0} / j_{0}^{*}\right)$ of this collection of enterococci amounts to $2 \cdot 1 \pm 0 \cdot 4$, which indicates that these strains have a high affinity for the hydrophobic substrata used.

\section{Number of bacteria adhering at the stationary end point}

The number of bacteria at the stationary end point $(n$ at $\left.t_{\infty}\right)$ in the flow chamber was significantly higher for $E$. faecalis with surface proteins compared to OG1X without surface proteins (Table 1). The mean total number of bacteria for all strains on FEP was significantly higher than on SR $(P \leqslant 0 \cdot 05)$.

\section{Characteristic adhesion time constant}

The characteristic adhesion time constant $\tau\left(=n_{\infty} j_{0}^{-1}\right)$ describes the way in which the adhesion process approaches a stationary state. For E. faecalis strains with surface proteins, $\tau$ is higher than for OG1X without surface proteins and for most strains this difference is significant, indicating that it takes longer for these bacteria to attain stationary state adhesion. No significant difference could be detected between the different substrata averaged over all strains.

\section{Positive cooperativity}

Positive cooperativity in microbial adhesion to surfaces is defined as the ability of one adhering organism to stimulate the adhesion of other organisms in its immediate vicinity. Originally, positive cooperativity was 


\section{Table 1. Adhesion of $E$. faecalis strains to three different bile drain materials}

Numbers show the initial deposition rate $\left(j_{0}\right)$, characteristic adhesion time $(\tau)$ and no. of bacteria at the stationary end point $\left(n\right.$ at $\left.t_{\infty}\right)$. Experiments performed in triplicate with separate bacterial cultures yielded an $\mathrm{SD}<30 \%$.

\begin{tabular}{|c|c|c|c|c|c|c|c|c|c|}
\hline \multirow[t]{2}{*}{ Strain } & \multicolumn{3}{|c|}{$10^{-2} \times j_{0}\left(\mathrm{~cm}^{-2} \mathrm{~s}^{-1}\right)$} & \multicolumn{3}{|c|}{$10^{-3} \times \tau\left(\mathrm{s}^{-1}\right)$} & \multicolumn{3}{|c|}{$10^{-6} \times n$ at $t_{\infty}\left(\mathrm{cm}^{-2}\right)$} \\
\hline & FEP & PE & SR & FEP & PE & SR & FEP & PE & SR \\
\hline OG1X $\left(\mathrm{Agg}^{-}, \mathrm{Esp}^{-}\right)$ & 16 & 16 & 8 & $3 \cdot 7$ & $2 \cdot 9$ & $3 \cdot 0$ & $6 \cdot 1$ & $4 \cdot 9$ & $2 \cdot 6$ \\
\hline OG1XE:pAD1 $\left(\mathrm{Agg}^{+}\right)$ & 17 & 16 & 10 & $8 \cdot 3 *$ & $5 \cdot 0$ & $11 \cdot 1^{*}$ & $14 \cdot 0 *$ & $8 \cdot 0 *$ & $11 \cdot 2 *$ \\
\hline OG1X:pWeAsa1 $\left(\mathrm{Agg}^{+}\right)$ & 17 & 16 & 12 & $8 \cdot 3 *$ & $8 \cdot 3 *$ & $6.7 *$ & $14 \cdot 9 *$ & $13 \cdot 3 *$ & $7 \cdot 8 *$ \\
\hline OG1X:pAM373 $\left(\mathrm{Agg}^{+}\right)$ & 16 & 12 & 13 & $7 \cdot 1^{*}$ & $7 \cdot 1^{*}$ & $6 \cdot 3 *$ & $11 \cdot 5 *$ & $8 \cdot 3 *$ & $7 \cdot 9 *$ \\
\hline MMH594 $\left(\mathrm{Esp}^{+}\right)$ & 17 & 16 & $18^{*}$ & $5 \cdot 9$ & $7 \cdot 7 *$ & $3 \cdot 8$ & $10 \cdot 3 *$ & $12 \cdot 6^{*}$ & $7 \cdot 1 *$ \\
\hline
\end{tabular}

$* P \leqslant 0 \cdot 05$ versus OG1X.
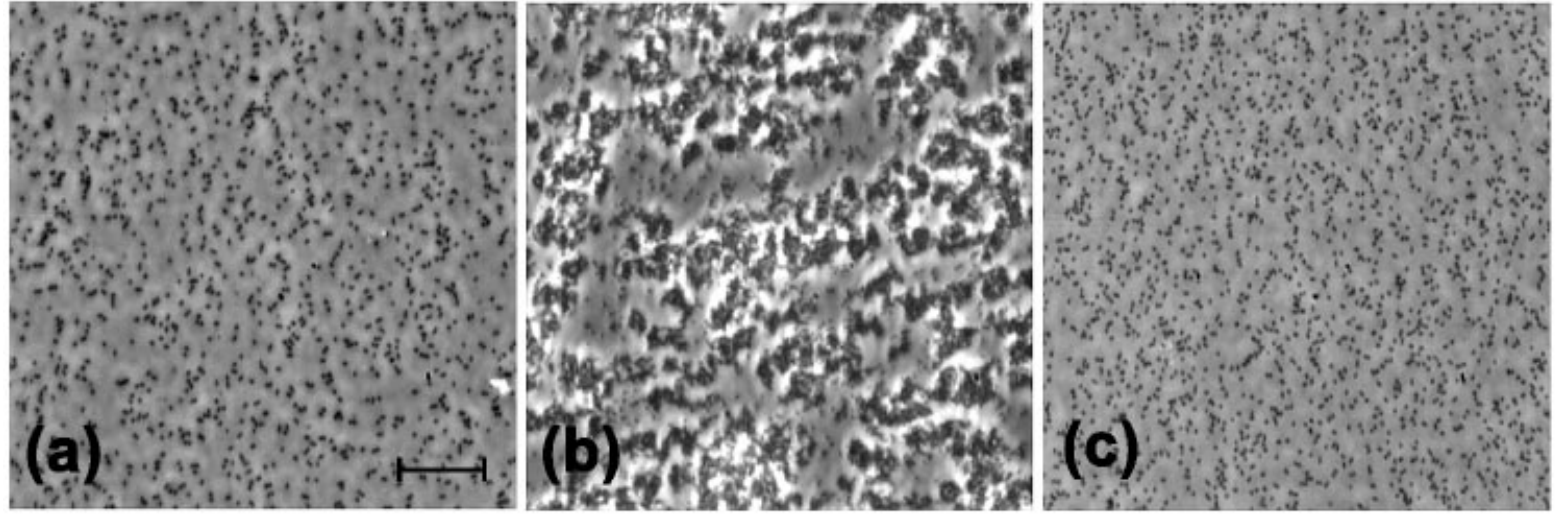

Fig. 1. Spatial arrangements of $E$. faecalis after $4 \mathrm{~h}$ of flow on FEP for OG1X (a), OG1XE:pAD1 (b) and MMH594 (c). The images show the presence of small aggregates of $E$. faecalis on the surface for OG1X (a), the formation of distinct aggregates if Agg is expressed (b) and the absence of aggregates if Esp is expressed (c). The distribution of OG1X:pWeAsa1 was very similar to OG1X, while the distribution of OG1X:pAM373 was very similar to OG1XE:pAD1; therefore, these images are not shown. Bar, $15 \mu \mathrm{m}$.

indirectly inferred from Scatchard plots of bound over unbound organisms. However, the Scatchard analysis involves several assumptions that are not always met for microbial adhesion (Van der Mei et al., 1993). Sjollema \& Busscher (1990) have pointed out that positive cooperativity is directly reflected in the spatial arrangement of adhering organisms over a substratum surface, provided the spatial arrangement is fully preserved as existing during adhesion. Positive cooperativity is then concluded from high local relative densities around a given adhering organism. The spatial arrangement of adhering enterococci over a substratum surface was analysed by radial pair distribution functions. Each adhering bacterium was taken once as a centre point and local densities of adhering enterococci were determined in circular shells at a distance $r$ from this centre point. These local densities were normalized with respect to the mean density of adhering bacteria, resulting in the radial pair distribution function $g(r)$. When enterococci are randomly distributed over the entire substratum surface, $g(r)=1$. However, if there is preferential adhesion at a given separation distance $r$ between adhering bacteria, then $g(r)>1$. The maximum value of $g\left(r_{\mathrm{p}}\right)$ indicates the preference for bacterial deposition near an already adhering bacterium and is a direct measure of positive cooperativity. The distance at which this maximum occurs $\left(r_{\mathrm{p}}\right)$ indicates the preferential adhesion distance of the bacteria. The maximum value of $g\left(r_{\mathrm{p}}\right)$ was calculated for three different fields of view after $4 \mathrm{~h}$ of flow.

Fig. 1 compares the spatial arrangements of strains OG1X, OG1XE:pAD1 and MMH594 on FEP after $4 \mathrm{~h}$ of flow and in Table 2 the accessory values for $g\left(r_{\mathrm{p}}\right)$ and $r_{\mathrm{p}}$ are shown. Previously, for inert polystyrene particles $g\left(r_{\mathrm{p}}\right)$ values ranging from $1 \cdot 2$ to $1 \cdot 4$ were reported, which provides a criterion for the absence of positive cooperativity (Sjollema \& Busscher, 1990). The strain used in 
Table 2. Degree of positive cooperativity involved in the adhesion of $E$. faecalis strains to FEP, PE and SR, as derived from radial distribution functions

Positive cooperativity is concluded from $g\left(r_{\mathrm{p}}\right)$ values in excess of 1.4 and $r_{\mathrm{p}}$ indicates the preferential adhesion distance. Experiments performed in triplicate with separate bacterial cultures yielded an $\mathrm{SD}<30 \%$.

\begin{tabular}{|c|c|c|c|c|c|c|}
\hline \multirow[t]{2}{*}{ Strain } & \multicolumn{3}{|c|}{$g\left(r_{\mathrm{p}}\right)$} & \multicolumn{3}{|c|}{$r_{\mathrm{p}}(\mu \mathrm{m})$} \\
\hline & FEP & $\mathrm{PE}$ & SR & FEP & PE & SR \\
\hline OG1X $\left(\mathrm{Agg}^{-}, \mathrm{Esp}^{-}\right)$ & $1 \cdot 4$ & $1 \cdot 8$ & $2 \cdot 3$ & $1 \cdot 2$ & $1 \cdot 2$ & $1 \cdot 3$ \\
\hline OG1XE:pAD1 $\left(\mathrm{Agg}^{+}\right)$ & $3 \cdot 2 *$ & $2 \cdot 7 *$ & $2 \cdot 8$ & $1 \cdot 8^{*}$ & $1 \cdot 7$ & $1 \cdot 8$ \\
\hline OG1X:pWeAsa1 $\left(\mathrm{Agg}^{+}\right)$ & $1 \cdot 7$ & $1 \cdot 5$ & $2 \cdot 2$ & $1 \cdot 8 *$ & $1 \cdot 9 *$ & $1 \cdot 5$ \\
\hline OG1X:pAM373 $\left(\mathrm{Agg}^{+}\right)$ & $2 \cdot 0$ & $2 \cdot 7 *$ & $2 \cdot 6$ & $1 \cdot 5^{*}$ & $1 \cdot 3$ & $1 \cdot 5$ \\
\hline MMH594 $\left(\mathrm{Esp}^{+}\right)$ & $1 \cdot 0$ & $1 \cdot 0 *$ & $1 \cdot 1 *$ & $2 \cdot 8 *$ & $2 \cdot 6^{*}$ & $2 \cdot 3 *$ \\
\hline
\end{tabular}

$* P \leqslant 0 \cdot 05$ versus OG1X.

this study can be divided into three groups with regard to their strength of cooperativity. (1) E. faecalis strains OG1X and OG1X:pWeAsa1 expressing weak, possibly non-specific cooperativity, as the spatial arrangement of strain OG1X shows mainly singly adhering organisms with some small aggregates (Fig. 1a). (2) E. faecalis strains OG1XE:pAD1 and OG1X:pAM373 expressing strong cooperativity, i.e. on the substratum surface distinct aggregates are formed (Fig. 1b), in line with an elevated value of $g\left(r_{\mathrm{p}}\right)$ (see Table 2). (3) Strain MMH594 adhering exclusively as single cells (Fig. 1c), i.e. $g\left(r_{\mathrm{p}}\right)$ equals unity, indicating the absence of positive cooperativity (see Table 2).

\section{DISCUSSION}

This study addressed the question whether different surface proteins on E. faecalis influence its adhesion to bile drain materials. Surface proteins do not influence the initial deposition of E. faecalis on different hydrophobic materials. However, the total number of bacteria adhering at the stationary end point was significantly higher for E. faecalis expressing surface proteins. The surface proteins enhance the total number of adhering bacteria via a different mechanism. The expression of Agg (Asa1 and Asa373) and other gene products encoded on the sex-pheromone plasmids, but not solely Agg (Asa1), invokes positive cooperativity. This means that adhering individual enterococci stimulate adhesion of more enterococci in the more advanced stages of the adhesion process, whereas the expression of Esp or solely Agg without the sex-pheromone plasmid enhances the number of adhering enterococci through direct interactions with the material and not via positive cooperativity.

The initial deposition rates reflect the direct interaction between the micro-organism and the substratum surface, without influences of already adhering bacteria (Bos et al., 1999). The initial contact between the bacterium and the substratum is determined by the presence of hydrophobic or electrostatic groups. When surface proteins are only scarcely present on the bacterial cell surface, these physico-chemical interaction forces will be influenced little by the presence of the surface proteins. Whereas the initial deposition rates vary little among the different strains, deposition rates of enterococci on FEP were higher than on PE and SR. This difference is likely to be a result of a combination of the high surface hydrophobicity of FEP and a different chemical composition. FEP is a very inert material with only fluorine groups on its surface, in contrast to, for example, SR with methyl groups on its surface (An \& Friedman, 1998).

In contrast to the initial deposition, the total number of bacteria at the stationary end point was increased by the presence of surface proteins on E. faecalis. The number of bacteria at the stationary end point is influenced not only by fundamental interaction forces originating from the substratum surface, but also by more specific interactions between the bacteria. Positive cooperativity is one of the mechanisms that might play a role in the increase in total number of bacteria if surface proteins are present. Adhesion of bacteria gives rise to new adhesion sites or diminishes the influence of antagonistic sites, and newly depositing bacteria will adhere preferably in the neighbourhood of already adhering ones. As a corollary of positive cooperativity, organisms adhere close to each other and appear not randomly distributed. Positive cooperativity on saliva-coated substrata has been explained predominantly by the capacity of adhering cells to induce conformational changes in the pellicle or on the surfaces of approaching cells (Doyle et al., 1982). However, positive cooperative phenomena have also been described for oral streptococci adhering to inert substrata (Van der Mei et al., 1993). Proposed explanations are based on the hypothesis that the magnitude of the interaction forces between adhering cells is higher than the interaction forces between adhering cells and their substrata or between cells in suspension (Doyle, 1991; Van der Mei et al., 1993).

A model for the adhesion of the different E. faecalis strains to an inert substratum surface, accounting for the role of surface proteins, is proposed in Fig. 2. The model shows three different mechanisms of adhesion to the substratum and interactions between bacteria, as found for the different strains in this study. Strain OG1X, without any surface proteins, shows a weak cooperativity between adhering enterococci that might be due to non-specific interactions (Fig. 2a). The E. faecalis strains expressing the sex-pheromone plasmids (OG1XE:pAD1 and OG1X:pAM373) adhere in high numbers to the substratum due to specific interaction between the bacteria (positive cooperativity) (Fig. 2b). This high cooperativity between sex-pheromone-plasmid-expressing bacteria might be explained by the fact that the plasmid plays a role in contact between bacteria for its own transfer (Wirth, 1994). The Esp-positive E. faecalis strain (MMH594) adheres in high numbers to the 
(a)

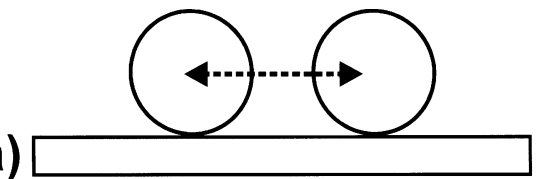

(b)

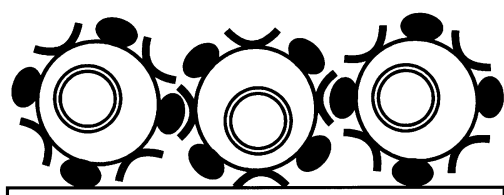

(c)
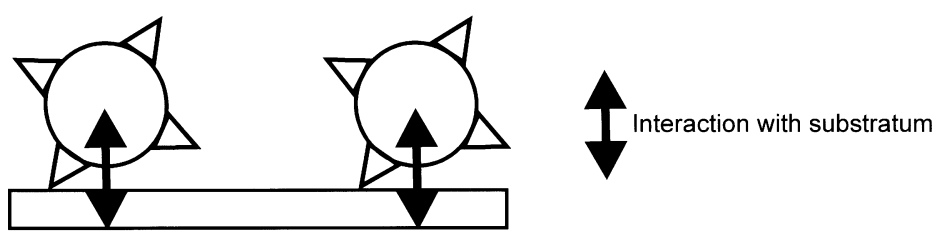

Receptor on surface of $E$. faecalis Aggregation substance $\triangle$ Enterococcal Surface protein

Sex-pheromone plasmid
Fig. 2. Proposed mechanism of the adhesion of $E$. faecalis with different surface proteins to hydrophobic substrata. (a) Strain OG1X without surface proteins shows weak cooperativity, possibly due to non-specific interactions and adheres in low numbers. (b) E. faecalis strains expressing the sexpheromone plasmids (OG1XE:pAD1 and OG1X:pAM373) adhere in high numbers to the substratum due to specific interaction between the bacteria (positive cooperativity). (c) Esp-positive E. faecalis strain MMH594 does not show any interaction between the bacteria, but yet adheres in high numbers to the substratum as a result of strong interaction forces with the substratum due to the presence of Esp on the surface. substratum, but does not show any interaction between the bacteria (Fig. 2c). Consequently, the interaction force with the substratum of this strain must be strong, possibly due to the presence of Esp on the surface. This result has been confirmed by a recent study (ToledoArana et al., 2001) in which it was shown that Esp increases the number of bacteria adhering to abiotic surfaces by comparing the adhesion with Esp-deficient mutants. Strain OG1X:pWeAsa1 expressing Asa1, but not the sex-pheromone plasmid, does not fit very well into this model. This strain adheres in high numbers, although its cooperativity is similar to that of strain OG1X. Both strain OG1X:pWeAsa1 as well as the strains that express the whole sex-pheromone plasmid showed high numbers of adhering bacteria at the stationary end point; this might indicate that not the whole sex-pheromone plasmid, but only Agg is necessary to reach high numbers of adhering bacteria. On the other hand, the lower cooperativity of strain OG1X:pWeAsa1 compared to the strains with the whole sex-pheromone plasmid indicates that other factors than Agg encoded on the sex-pheromone plasmid play a role in positive cooperativity. The difference in cooperativity could also be explained by differences in the expression level of Agg between OG1X:pWeAsa1 and OG1XE:pAD1, since the promoter constructed in OG1X:pWeAsa1 is weaker than the promoter constructed in OG1XE:pAD1 (Albrecht B. MuschollSilberhorn, personal communication). However, a similar level of expression was seen in the immunofluorescence assay, which indicates that the difference in expression might not be very high. The sex-pheromone plasmid transfer system is very complicated with many factors involved in its control. The functions of some genes on the plasmids are still not completely understood today (De Boever et al., 2000; Dunny et al., 1995;
Francia et al., 2001; Wirth, 1994). The question of which of these factors is involved in positive cooperativity on the surface is intriguing and still needs to be answered more fully.

The surface proteins described in this paper are possible virulence factors associated with infections in humans. However, the exact role of these proteins in the pathogenesis of infections is still not known. Many of the infections in hospitalized patients are associated with in-dwelling medical devices, especially bile drains. One way of initiating these biomaterial-centred infections is by adhesion to the device. In this study we found that the surface proteins of E. faecalis are possible virulence factors because they enhance the number of bacteria adhering to bile drain materials. Higher total numbers of bacteria adhering to in-dwelling medical devices may lead to more colonization and biomaterialcentred infections. In addition, the question might arise whether the surface proteins studied under in vitro conditions will be expressed in patients. Esp is always expressed on the surface if the bacterium contains the esp gene, therefore it is likely to be expressed in vivo (Shankar et al., 1999). The in vivo expression of Agg is more difficult to describe. To our knowledge until now no research has been published on the expression of Agg in bile or the human gut. However, it has been shown that factors other than pheromone (e.g. serum) can induce expression of Agg in vivo (Hirt et al., 2000; Kreft et al., 1992). Therefore, we think that it is reasonable to assume that Agg is expressed in vivo.

In summary, enterococci expressing Esp or Agg adhere in higher numbers to hydrophobic bile drain materials. However, E. faecalis with different surface proteins adheres to the substratum through different mechanisms. Enterococci expressing the sex-pheromone plas- 
mid encoding Asa1 or Asa373 adhere in high numbers through positive cooperativity between adhering bacteria. Enterococci positive for Esp also adhere in high numbers, but do not utilize positive cooperative mechanisms in their adhesion to these materials. These findings indicate that interfering with the positive cooperativity between adhering enterococci, as resulting from the expression of sex-pheromone plasmids, or interfering with the interaction between surface proteins and materials, might yield a way to prevent bile-drainassociated infections.

\section{ACKNOWLEDGEMENTS}

We thank Albrecht Muscholl-Silberhorn for helpful discussion. We also thank Rudi Tonk and Joop de Vries for reproduction of the figures in this article.

\section{REFERENCES}

An, Y. H. \& Friedman, R. J. (1998). Concise review of mechanisms of bacterial adhesion to biomaterial surfaces. J Biomed Mater Res 43, 338-348.

Ben-Ari, Z., Neville, L., Davidson, B., Rolles, K. \& Burroughs, A. K. (1998). Infection rates with and without T-tube splintage of common bile duct anastomosis in liver transplantation. Transplant Int 11, 123-126.

Berti, M., Candiani, G., Kaufhold, A., Muscholl, A. \& Wirth, R. (1998). Does aggregation substance of Enterococcus faecalis contribute to development of endocarditis? Infection 26, 48-53.

Bos, R., Van der Mei, H. C. \& Busscher, H. J. (1999). Physicochemistry of initial microbial adhesive interactions - its mechanisms and methods for study. FEMS Microbiol Rev 23, 179-230.

Bowen, B. D., Levine, S. \& Epstein, N. (1976). Fine particles depostion in laminar flow through parallel plate and cylindrical channels. J Colloid Interface Sci 54, 375-390.

Busscher, H. J. \& Van der Mei, H. C. (1995). Use of flow chamber devices and image analysis methods to study microbial adhesion. Methods Enzymol 253, 455-477.

Busscher, H. J., Bos, R., Van der Mei, H. C. \& Handley, P. S. (2000). Physicochemistry of microbial adhesion from an overall approach to the limits. In Physical Chemistry of Biological Interfaces, pp. 431-458. Edited by A. Baszkin \& others. New York, Basel: Marcel Dekker.

Clewell, D. B. (1993). Bacterial sex pheromone-induced plasmid transfer. Cell 73, 9-12.

Clewell, D. B., An, F. Y., White, B. A. \& Gawron-Burke, C. (1985). Streptococcus faecalis sex pheromone (cAM373) also produced by Staphylococcus aureus and identification of a conjugative transposon (Tn918). J Bacteriol 162, 1212-1220.

Coque, T. M., Patterson, J. E., Steckelberg, J. M. \& Murray, B. E. (1995). Incidence of hemolysin, gelatinase, and aggregation substance among enterococci isolated from patients with endocarditis and other infections and from feces of hospitalized and community-based persons. J Infect Dis 171, 1223-1229.

Costerton, J. W., Stewart, P. S. \& Greenberg, E. P. (1999). Bacterial biofilms: a common cause of persistent infections. Science 284, 1318-1322.

Dabros, T. \& Van de Ven, T. G. M. (1982). Kinetics of coating by colloid particles. J Colloid Interface Sci 89, 232-244.

De Boever, E. H., Clewell, D. B. \& Fraser, C. M. (2000). Enterococcus faecalis conjugative plasmid pAM373: complete nucleo- tide sequence and genetic analyses of sex pheromone response. Mol Microbiol 37, 1327-1341.

Doyle, R. J. (1991). Strategies in experimental microbial adhesion research. In Microbial Cell Surface Analysis-Structural and Physicochemical Methods, pp. 291-316. Edited by N. Mozes \& others. New York: VCH.

Doyle, R. J., Nesbitt, W. E. \& Taylor, K. G. (1982). On the mechanism of adhesion of Streptococcus sanguis to hydroxylapatite. FEMS Microbiol Lett 15, 1-5.

Dunny, G. M., Leonard, B. A. \& Hedberg, P. J. (1995). Pheromoneinducible conjugation in Enterococcus faecalis: interbacterial and host-parasite chemical communication. J Bacteriol 177, 871-876.

Francia, M. V., Haas, W., Wirth, R. \& 7 other authors (2001). Completion of the nucleotide sequence of the Enterococcus faecalis conjugative virulence plasmid pAD1 and identification of a second transfer origin. Plasmid 46, 117-127.

Franke, A. E. \& Clewell, D. B. (1981). Evidence for a chromosomeborne resistance transposon (Tn916) in Streptococcus faecalis that is capable of 'conjugal' transfer in the absence of a conjugative plasmid. J Bacteriol 145, 494-502.

Galli, D. \& Wirth, R. (1991). Comparative analysis of Enterococcus faecalis sex pheromone plasmids identifies a single homologous DNA region which codes for aggregation substance. J Bacteriol 173, 3029-3033.

Galli, D., Wirth, R. \& Wanner, G. (1989). Identification of aggregation substances of Enterococcus faecalis cells after induction by sex pheromones. An immunological and ultrastructural investigation. Arch Microbiol 151, 486-490.

Galli, D., Lottspeich, F. \& Wirth, R. (1990). Sequence analysis of Enterococcus faecalis aggregation substance encoded by the sex pheromone plasmid pAD1. Mol Microbiol 4, 895-904.

Hirt, H., Antiporta, M. H., Waters, C. M., McCormick, J. K., Schlievert, P. M. \& Dunny, G. M. (2000). In vivo expression and role of aggregation substance in experimental endocarditis. In Abstract of the 1st International ASM Conference on Enterococci: Pathogenesis, Biology, and Antibiotic Resistance, abstract S14, pp. 15-16. Banff, Alberta, Canada: American Society for Microbiology.

Ike, Y., Craig, R. A., White, B. A., Yagi, Y. \& Clewell, D. B. (1983). Modification of Streptococcus faecalis sex pheromones after acquisition of plasmid DNA. Proc Natl Acad Sci USA 80, 5369-5373.

Jacob, A. E. \& Hobbs, S. J. (1974). Conjugal transfer of plasmidborne multiple antibiotic resistance in Streptococcus faecalis var. zymogenes. J Bacteriol 117, 360-372.

Jett, B. D., Huycke, M. M. \& Gilmore, M. S. (1994). Virulence of enterococci. Clin Microbiol Rev 7, 462-478.

Koivusalo, A., Makisalo, H., Talja, M., Siitonen, A., VuopioVarkila, J., Ruutu, M. \& Hockerstedt, K. (1996). Bacterial adherence and biofilm formation on latex and silicone T-tubes in relation to bacterial contamination of bile. Scand J Gastroenterol 31, 398-403.

Kreft, B., Marre, R., Schramm, U. \& Wirth, R. (1992). Aggregation substance of Enterococcus faecalis mediates adhesion to cultured renal tubular cells. Infect Immun 60, 25-30.

Molinari, G., Pugliese, V., Schito, G. C. \& Guzman, C. A. (1996). Bacteria involved in the blockage of biliary stents and their susceptibility to antibacterial agents. Eur J Clin Microbiol Infect Dis 15, 88-92.

Murray, B. E. (1990). The life and times of the Enterococcus. Clin Microbiol Rev 3, 46-65.

Muscholl, A., Galli, D., Wanner, G. \& Wirth, R. (1993). Sex 
pheromone plasmid pAD1-encoded aggregation substance of Enterococcus faecalis is positively regulated in trans by traE1. Eur J Biochem 214, 333-338.

Muscholl-Silberhorn, A. (1999). Cloning and functional analysis of Asa373, a novel adhesin unrelated to the other sex pheromone plasmid-encoded aggregation substances of Enterococcus faecalis. Mol Microbiol 34, 620-630.

Olmsted, S. B., Dunny, G. M., Erlandsen, S. L. \& Wells, C. L. (1994). A plasmid-encoded surface protein on Enterococcus faecalis augments its internalization by cultured intestinal epithelial cells. J Infect Dis 170, 1549-1556.

Ruoslahti, E. (1996). RGD and other recognition sequences for integrins. Annu Rev Cell Dev Biol 12, 697-715.

Sartingen, S., Rozdzinski, E., Muscholl-Silberhorn, A. \& Marre, R. (2000). Aggregation substance increases adherence and internalization, but not translocation, of Enterococcus faecalis through different intestinal epithelial cells in vitro. Infect Immun $\mathbf{6 8}$, 6044-6047.

Shankar, V., Baghdayan, A. S., Huycke, M. M., Lindahl, G. \& Gilmore, M. S. (1999). Infection-derived Enterococcus faecalis strains are enriched in esp, a gene encoding a novel surface protein. Infect Immun 67, 193-200.

Shankar, N., Lockatell, C. V., Baghdayan, A. S., Drachenberg, C., Gilmore, M. S. \& Johnson, D. E. (2001). Role of Enterococcus faecalis surface protein Esp in the pathogenesis of ascending urinary tract infection. Infect Immun 69, 4366-4372.

Sjollema, J. \& Busscher, H. J. (1990). Deposition of polystyrene particles in a parallel plate flow cell. 2. Pair distribution functions between deposited particles. Colloids Surfaces 47, 337-352.

Toledo-Arana, A., Valle, J., Solano, C. \& 7 other authors (2001). The Enterococcal Surface Protein, Esp, is involved in Enterococcus faecalis biofilm formation. Appl Environ Microbiol 67, $4538-4545$

Van der Mei, H. C., Cox, S. D., Geertsema-Doornbusch, G. I., Doyle, R. J. \& Busscher, H. J. (1993). A critical appraisal of positive cooperativity in oral streptococcal adhesion: Scatchard analyses of adhesion data versus analyses of the spatial arrangement of adhering bacteria. J Gen Microbiol 139, 937-948.

Willems, R. J., Homan, W., Top, J. \& 9 other authors (2001). Variant esp gene as a marker of a distinct genetic lineage of vancomycin-resistant Enterococcus faecium spreading in hospitals. Lancet 357, 853-855.

Wirth, R. (1994). The sex pheromone system of Enterococcus faecalis. More than just a plasmid-collection mechanism? Eur J Biochem 222, 235-246.

Yu, J. L., Andersson, R. \& Ljungh, A. (1996a). Infections associated with biliary drains. Scand J Gastroenterol 31, 625-630.

Yu, J. L., Andersson, R., Parsson, H., Hallberg, E., Ljungh, A. \& Bengmark, S. (1996b). A bacteriologic and scanning electron microscope study after implantation of foreign bodies in the biliary tract in rats. Scand J Gastroenterol 31, 175-181.

Received 29 August 2001; revised 30 January 2002; accepted 5 February 2002. 